\title{
Cysteine String Proteins Associated with Secretory Granules of the Rat Neurohypophysis
}

\author{
Sandrine Pupier, ${ }^{1}$ Christian Leveque, ${ }^{1}$ Beatrice Marqueze, ${ }^{1}$ Masakazu Kataoka, ${ }^{2}$ Masami Takahashi, ${ }^{2}$ and \\ Michael J. Seagar ${ }^{1}$ \\ 1/nstitut National de la Santé et de la Recherche Médicale U464, Institut Jean Roche, Faculté de Médecine Secteur Nord, \\ 13916 Marseille Cedex 20, France, and 2Mitsubishi Kasei Institute of Life Science, Machida, 194 Tokyo, Japan
}

The properties and subcellular distribution of cysteine string proteins (csps) were analyzed in peptidergic nerve terminals of the rat neurohypophysis. Polyclonal antibodies raised against recombinant rat brain csp recognized a $36 \mathrm{kDa}$ protein in isolated neurosecretosomes from the post-pituitary. After chemical deacylation, a single $27 \mathrm{kDa}$ form was detected that displayed identical properties to csps in a whole-brain synaptosomal fraction. Immunoisolation demonstrated that synaptophysin and csps were located in the same vesicles. Density gradient centrifugation of postsynaptosomal supernatants of neurohypophysial homogenates revealed that csps and VAMP were present in two distinct vesicle populations. Synaptophysin was only detected in the slowly migrating population corresponding to small synaptic vesicles, whereas arginine vasopressin was present in the more rapidly sedimenting population indicating that it contains large dense core vesicles (LDCVs). Immobilized antibodies against csp, synaptotagmin, or VAMP captured vesicular arginine vasopressin confirming the association of these proteins with LDCVs. Co-immunoprecipitation assays with proteins solubilized from neurohypophysial or whole-brain nerve terminals failed to reveal complexes containing csp and $\left[{ }^{125} \mathrm{I}\right] \omega \mathrm{GVIA}$ receptors. These results indicate that csps in the CNS are associated with both small synaptic vesicles and LDCVs. However, they do not provide support for the hypothesis that protein complexes implicated in exocytosis, which interact with presynaptic N-type calcium channels, contain csps.

Key words: cysteine string proteins; VAMP; calcium channels; large dense core vesicles; synaptic vesicles; neurohypophysis
Neurotransmitter release is triggered by calcium influx through voltage-gated calcium channels, and much progress has been achieved in recent years in identifying proteins and proteinprotein interactions involved in the trafficking, docking, and calcium-dependent exocytosis of secretory vesicles (for review, see Martin, 1994; Sudhof, 1995; Augustine et al., 1996).

Cysteine string proteins (csps) were first discovered in Drosophila as antigens recognized by a monoclonal antibody that selectively stains neuropil regions and synaptic boutons (Zinsmaier et al., 1990) and were subsequently shown to be expressed in fish (Gundersen and Umbach, 1992) and mammals (Mastrogiacomo and Gundersen, 1995; Chamberlain and Burgoyne, 1996; Chamberlain et al., 1996; Coppola and Gundersen, 1996). Csps contain a fatty acylated string of cysteine residues (Gundersen et al., 1994) and a $\mathbf{J}$ domain homologous to motifs in bacterial DnaJ proteins that regulate the chaperon activity of DnaK, a Hsp70-like protein (for review, see Cyr et al., 1994).

The precise role of csps is unknown, although they appear to be involved in evoked neurotransmitter release. Deletion of the csp gene in Drosophila causes temperature-sensitive failure of synaptic transmission resulting in paralysis and death (Zins-

Received Oct. 24, 1996; revised Jan. 13, 1997; accepted Feb. 4, 1997.

This work was supported by a joint program of the Institut National de la Santé et de la Recherche Médicale and the Japanese Society for the Promotion of Science, and a grant to S.P. from the Institut Scientifique Roussel. We are grateful to Dr. Cameron Gundersen for providing rat csp cDNA.

Correspondence should be addressed to Dr. Michael J. Seagar, Institut National de la Santé et de la Recherche Médicale U464, Faculté de Médecine Secteur Nord, Boulevard Pierre Dramard, 13916 Marseille Cedex 20, France.

Copyright (C) 1997 Society for Neuroscience $0270-6474 / 97 / 172722-06 \$ 05.00 / 0$ maier et al., 1994), the defect being attributable to impaired depolarization-secretion coupling at nerve terminals (Umbach et al., 1994).

A cDNA encoding a highly homologous Torpedo csp was independently isolated in a cloning strategy designed to identify components necessary for the functional expression of presynaptic $\omega$-CTx-GVIA ( $\omega$ GVIA)-sensitive calcium channels in Xenopus oocytes (Gundersen and Umbach, 1992). Although Torpedo csps seem to act as positive regulators of calcium channels in the plasma membrane, in the electric organ, they are apparently localized at the cytoplasmic surface of synaptic vesicles (Mastrogiacomo et al., 1994). This led to the proposal that subsequent to vesicle docking at the plasma membrane, interactions between the calcium channel and csp may be necessary for channels associated with docked vesicles to open in response to depolarization (Mastrogiacomo et al., 1994).

At least two types of secretory vesicle participate in calciumdependent exocytosis in the CNS. Neurotransmitters such as glutamate, acetylcholine, and GABA are stored in small synaptic vesicles (SSVs), and release occurs with a submillisecond delay after calcium influx. In contrast, the secretion of peptides and neurohormones from large dense core vesicles (LDCVs) displays a significantly slower response to calcium elevation (Martin, 1994; Augustine et al., 1996). The molecular basis for the difference in latency is not understood but may involve differences in protein composition between the two types of vesicles. Thus, we have examined the subcellular distribution of csps and explored their interaction with presynaptic calcium channels in peptidergic terminals of the rat neurohypophysis, which contain both SSVs and LDCVs. 


\section{MATERIALS AND METHODS}

Antibody preparation. Monoclonal antibodies against synaptotagmin (mAb1D12), syntaxin 1 (mAb10H5), and synaptophysin (mAb171B5), provided by Dr. S. Fujita, Mitsubishi Kasei Institute of Life Science, Tokyo, and a polyclonal antibody against residues 2-20 of VAMP2 were prepared as reported previously (Takahashi et al., 1991; Yoshida et al., 1992; Oho et al., 1995). A maltose binding protein (MBP)-csp fusion protein was prepared using the New England Biolabs Protein Fusion and Purification System. A plasmid encoding the entire coding sequence of csp (Mastrogiacomo and Gundersen, 1995) was constructed by selective PCR amplification of rat csp cDNA (provided by Dr. C. Gundersen) using oligonucleotides containing flanking restriction sites. The resulting PCR fragment was then cloned into the pMAL vector (New England Biolabs, Beverly, MA). Recombinant proteins were purified by affinity chromatography on an amylose column (New England Biolabs) and stored at $-80^{\circ} \mathrm{C}$. Antibodies against MBP-csp were produced in rabbits, and IgG fractions were purified on Protein A-Sepharose Fast Flow beads (Pharmacia, Dorval, Québec, Canada).

Peptides. $\omega$ GVIA (Peptide Institute, Osaka) and arginine vasopressin (AVP, Sigma, St. Louis, MO) were radioiodinated by the Iodogen method and $\left[\right.$ mono $\left.^{125} \mathrm{I}\right]$ iodinated peptide derivatives $(2200 \mathrm{Ci} / \mathrm{mmol})$ were purified by reverse-phase HPLC on an analytical C18 column (Beckmann).

Subcellular fractionation. Isolated rat neurohypophysial nerve endings were prepared as described by Cazalis et al. (1987). The terminals were dissociated by homogenizing the posterior lobes of the pituitary in $0.32 \mathrm{M}$ sucrose and $10 \mathrm{~mm}$ HEPES, adjusted to $\mathrm{pH} 7.4$, with Tris containing the complete protease inhibitor mixture (Boehringer Mannheim, Indianapolis, IN), pelleted at $10000 \times g$ for $10 \mathrm{~min}$, and washed once by resuspension in the same buffer. To fractionate vesicles that were released during homogenization, $10000 \times g$ supernatants were pooled, loaded onto a continuous $0.4-2 \mathrm{M}$ sucrose gradient, and centrifuged at $65000 \times g$ for 5 hr (Navone et al., 1989). Immunoisolation of vesicles was performed, using a modification of the method introduced by Burger et al. (1989), and antibodies directed against csp or cytoplasmic epitopes of synaptotagmin, VAMP2, or synaptophysin. $10000 \times g$ neurohypophysial supernatants or $27000 \times g$ whole-brain supernatants were diluted in PBS containing $0.3 \%$ BSA buffer, and $100 \mu \mathrm{l}$ portions were incubated for $2 \mathrm{hr}$ at $4^{\circ} \mathrm{C}$ with $10 \mu \mathrm{g} \mathrm{IgG}$. Protein-A Sepharose Fast Flow beads (Pharmacia Biotech), saturated with 5\% BSA in PBS then washed once with PBS $0.3 \%$ BSA were added. Antibody-vesicle complexes were then recovered by mixing with the beads for $1 \mathrm{hr}$ at $4^{\circ} \mathrm{C}$ and centrifuging for $30 \mathrm{sec}$ at $10000 \times g$ and washed three times in PBS, $0.3 \%$ BSA. The washed pellet was resuspended in $250 \mu \mathrm{l}$ of the same buffer containing $1 \%$ Triton X-100. After a $30 \mathrm{sec}$ centrifugation at $10000 \times g$, the AVP content of the supernatant was measured by radioimmunoassay.

Deacylation, SDS-PAGE, and Western blotting. MBP-csp was cleaved with Factor Xa, and csp was recovered by chromatography on an amylose column. Rat brain csp was deacylated in $0.1 \mathrm{M} \mathrm{KOH}$ in methanol for $1 \mathrm{hr}$ at $22^{\circ} \mathrm{C}$ (Gundersen et al., 1994), then neutralized with $\mathrm{HCl}$. Controls were treated with methanol alone. Solvent was evaporated before electrophoresis. Proteins were denatured at $100^{\circ} \mathrm{C}$ for $1 \mathrm{~min}$ in SDS-PAGE sample buffer containing $10 \mathrm{~mm}$ dithiothreitol. SDS-PAGE and Western blotting were performed as described previously (Leveque et al., 1994). Blots were probed with $30 \mu \mathrm{g} / \mathrm{ml}$ anti-csp IgG, whereas all other antibodies were used at $10 \mu \mathrm{g} / \mathrm{ml}$. Detection was achieved using Protein A-peroxidase and an ECL kit (Amersham).

Radioimmunoassay. The AVP content of immunobead-isolated material was measured by radioimmunoassay using anti-AVP antiserum, kindly provided by Dr. G. Rougon (Laboratoire de Génétique et Physiologie du Développement, Marseille, France) and used at a final dilution of 1:10000. Separation of bound AVP from free AVP was accomplished by adsorption of the free fraction on activated charcoal.

Immunoprecipitation of calcium channels. Nerve terminals were prelabeled with $0.1 \mathrm{~nm}\left[{ }^{125} \mathrm{I}\right] \omega \mathrm{GVIA}$ and solubilized in CHAPS, and immunoprecipitation experiments were performed as described by Leveque et al. (1994).

\section{RESULTS}

Antibodies were raised against rat csp fused to MBP, and their ability to react with purified recombinant rat csp, csp in rat brain P2 membranes, and isolated nerve terminals from the neurohypophysis was tested by immunoblotting. Antibodies reacted with a single major protein band in each lane (Fig. 1A, lanes 1-3).

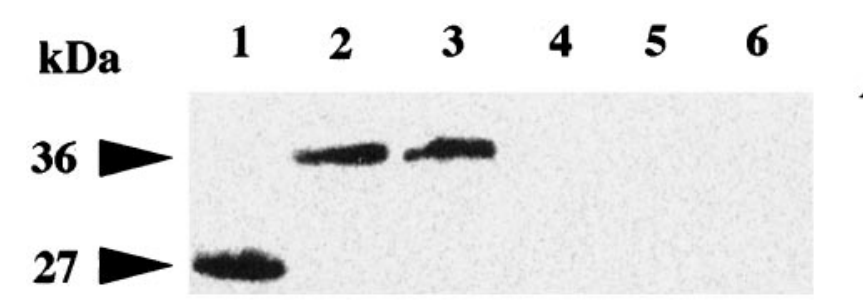

$\mathbf{A}$

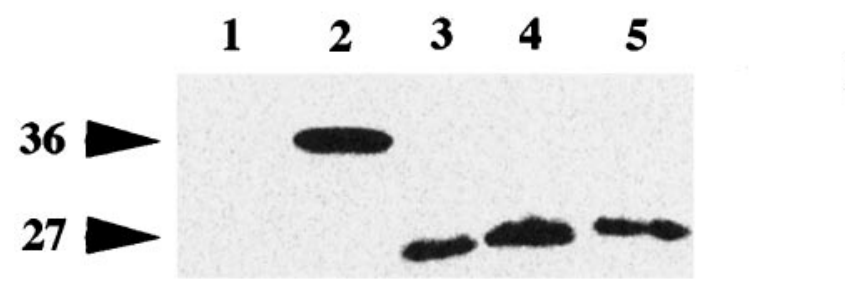

B

Figure 1. Cysteine string proteins in nerve terminals of the neurohypophysis. A, Recombinant csp (lanes 1, 4), rat brain P2 membranes (lanes 2, 5 ), and neurohypophysial nerve terminals (lanes 3,6 ) were separated by $12 \%$ SDS-PAGE, blotted, and probed with anti-rat csp antibodies (lanes 1-3). In control experiments, antibodies were preincubated with recombinant $\operatorname{csp}$ for $12 \mathrm{hr}$ (lanes $4-6$ ). Immunoreactive bands were visualized by ECL. $B$, Rat neurohypophysial nerve terminals were solubilized with $1 \%$ CHAPS and immunoprecipitated with $20 \mu \mathrm{g}$ control IgG (lane 1) or anti-csp IgG (lane 2) in a final volume of $0.2 \mathrm{ml}$. Recombinant csp (lane 3) and csps from rat brain (lane 4) or rat neurohypophysis (lane 5) were deacylated by treatment with methanolic $\mathrm{KOH}$. Immunoblots were probed with anti-csp antibodies.

Bacterially expressed csp migrated at $27 \mathrm{kDa}$ (Fig. 1A, lane 1) in reasonable agreement with the calculated molecular mass, whereas the protein band in brain $\mathrm{P} 2$ membranes (Fig. 1A, lane 2) and neurohypophysis (Fig. $1 A$, lane 3 ) migrated at $36 \mathrm{kDa}$. Immunoreactivity was specific for csp, because it was blocked by preincubating antibodies with an excess of purified recombinant csp (Fig. 1A, lanes 4-6).

To compare the degree of fatty acylation of csps in P2 membranes and neurohypophysial nerve terminals, proteins were delipidated by treatment with $0.1 \mathrm{M} \mathrm{KOH}$ in methanol. Csps were detected by immunoblotting after immunoprecipitation with anticsp antibodies (Fig. 1B, lane 2), but not after control IgG (Fig. 1B, lane 1). After deacylation, csp from P2 membranes (Fig. 1B, lane 4 ) and the neurohypophysis (lane 5) migrated at $27 \mathrm{kDa}$, as with bacterially expressed csp (lane 3 ). These data indicate that a single-size form of csp is expressed in peptidergic nerve terminals of the rat brain, which displays similar lipid content and core polypeptide mass to csp in total brain P2 membranes. Dimeric forms of the csp protein with an apparent molecular mass of 70 $\mathrm{kDa}$ were also often detected (data not shown) when denatured proteins were stocked, but not when SDS-PAGE was performed immediately after denaturation.

Immobilized anti-synaptophysin antibodies can be used to immunoisolate SSVs (Burger et al., 1989). To determine whether csp was associated with SSVs in the neurohypophysis, the ability of anti-csp antibodies to capture vesicles containing synaptophysin was compared with that of anti-synaptophysin antibodies. Postsynaptosomal supernatants from homogenized neurohypophyses contain vesicles released during homogenization. Aliquots of these supernatants were incubated with anticsp, anti-synaptophysin, or control antibodies linked to Protein A-Sepharose beads, and synaptophysin was detected by Western blotting. Both anti-csp and anti-synaptophysin antibodies, but not nonimmune IgG, trapped membranes containing syn- 


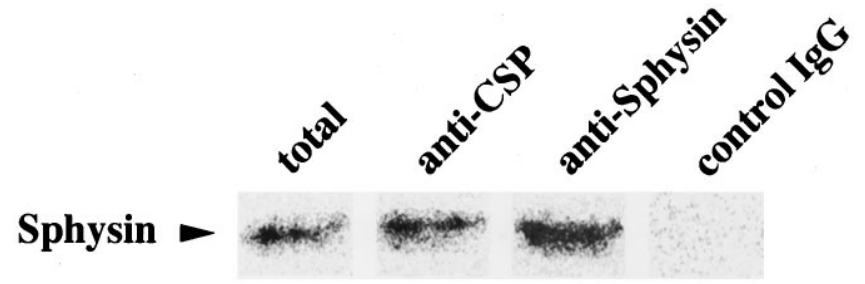

Figure 2. Immunoisolation of vesicles containing synaptophysin from the neurohypophysis. Postsynaptosomal supernatants containing vesicles released during homogenization of neurohypophyses were incubated with $10 \mu \mathrm{g}$ anti-csp, $1 \mu \mathrm{g}$ anti-synaptophysin, or $10 \mu \mathrm{g}$ control $\mathrm{IgG}$, and immune complexes were recovered on Protein A beads. In the lane labeled total, an aliquot corresponding to half of the amount of protein used in immunoisolation assays was loaded directly onto the SDS gel. Immunoblots of the captured vesicle proteins were probed with anti-synaptophysin antibodies, and quantification was performed by densitometric scanning (see text).

aptophysin (Fig. 2). In these experiments, anti-csp and antisynaptophysin antibodies were able to capture 72 and 93\%, respectively, of total synaptophysin. These results demonstrate that in peptidergic terminals of the neurohypophysis, csp is expressed in a population of vesicles that also contains synaptophysin.

Because terminals in the neurohypophysis contain both SSVs and LDCVs, the distribution of csp was compared with that of other vesicular markers after fractionation by centrifugation on a linear sucrose gradient. Csps were not detected in fractions at the entry to the gradient, which contain soluble cytoplasmic proteins, but were identified in two distinct peaks centered on fractions 8-13 and 17-20 (Fig. 3A), which also contained VAMP. Synaptophysin, which is considered to be a marker for SSVs, was concentrated only in the lighter peak (fractions 8-13). In contrast, AVP, which is contained in LDCVs, was primarily located in fractions $17-20$ (Fig. 3B). Fractions $1-5$ contained free AVP that was presumably released by partial vesicle lysis during homogenization and fractionation. These observations suggest that csp, like VAMP, is associated with both microvesicles and an LDCV fraction in peptidergic nerve terminals.

To eliminate the possibility that csp and AVP are present in distinct vesicle populations with similar sedimentation characteristics, we examined whether anti-csp antibodies could capture vesicles containing AVP. Using a procedure identical to experiments illustrated in Figure 2, postsynaptosomal supernatants from the neurohypophysis were incubated with beads coated with anticsp antibodies and antibodies against cytoplasmic domains of the vesicular transmembrane proteins VAMP, synaptotagmin, and synaptophysin. Trapped vesicles were then washed and lysed, and released AVP was measured by radioimmunoassay. However, because experiments were performed with an excess of postsynaptosomal supernatant only a fraction of the total AVP was recovered. Antibodies against csp (8\%), VAMP (15\%), and synaptotagmin (9\%) all captured higher amounts of AVP than control rabbit $(1.5 \%)$ or mouse IgGs (1.5\%) (Fig. 4). These results confirm that csp, like synaptotagmin and VAMP, is expressed in LDCVs containing AVP and is accessible to antibodies at the cytoplasmic surface of vesicles. Anti-synaptophysin antibodies trapped less AVP than anti-csp antibodies (Fig. 4), although Figure 2 demonstrates that in identical conditions, they are as efficient as anti-csp antibodies at capturing neurohypophysial vesicular membrane proteins. However anti-synaptophysin antibod-
A

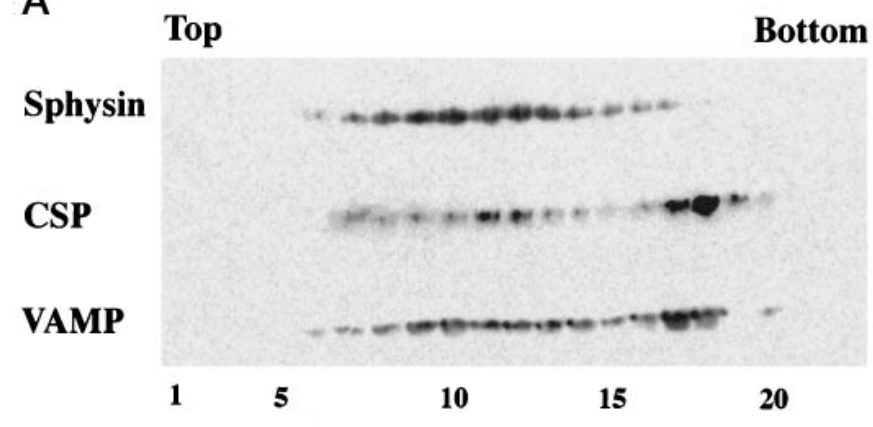

B

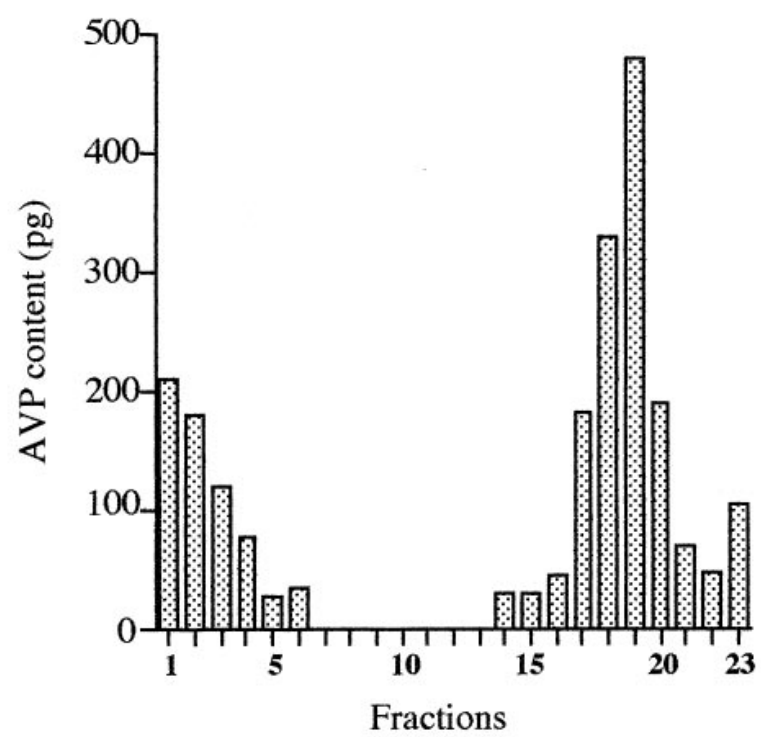

Figure 3. Distribution of vesicular proteins in synaptic vesicles and large dense core granules from the rat neurohypophysis. Postsynaptosomal supernatants containing vesicles released during homogenization of the neurohypophysis were loaded onto $0.4-2 \mathrm{~m}$ sucrose density gradients and spun for $5 \mathrm{hr}$ at $65000 \times \mathrm{g}$. A, Fractions were collected, and $0.16 \mathrm{ml}$ of each fraction was analyzed by SDS-PAGE and immunoblotted with antibodies against synaptophysin, csp, and VAMP. The illustrated data were taken from three separate immunoblots. Proteins were detected by incubation with secondary antibodies coupled to peroxidase and ECL. $B$, The AVP content of an equal volume of each fraction from the density gradient was determined by radioimmunoassay.

ies recovered significantly more AVP (paired Student's $t$ test, $p<$ 0.01, $n=12$ ) than did control antibodies (see Discussion).

It has been suggested that when vesicles dock at the plasma membrane, the interaction of csp with N-type calcium channels may control channel activity (Mastrogiacomo et al., 1994). Therefore, we examined the ability of csp antibodies to coimmunoprecipitate N-type calcium channels solubilized from peptidergic terminals of the neurohypophysis or brain P2 membranes and labeled with a specific radioligand $\left[{ }^{125} \mathrm{I}\right] \omega \mathrm{GVIA}$. Parallel control experiments were performed with antibodies against syntaxin 1, a protein involved in vesicular trafficking that binds to the $\alpha_{1} \mathrm{~B}$ subunit of the $\mathrm{N}$-type calcium channel (Yoshida et al., 1992; Leveque et al., 1994; Sheng et al., 1995). The data illustrated in Figure 5 demonstrate that anti-csp did not capture more CHAPS-extracted calcium channels than did nonimmune $\mathrm{IgG}$, whereas antibodies against syntaxin immunoprecipitated $\sim 50 \%$. Therefore, although anti-csp antibodies immunoprecipitated solubilized (Fig. $1 B$ ) or vesicle-bound csp 


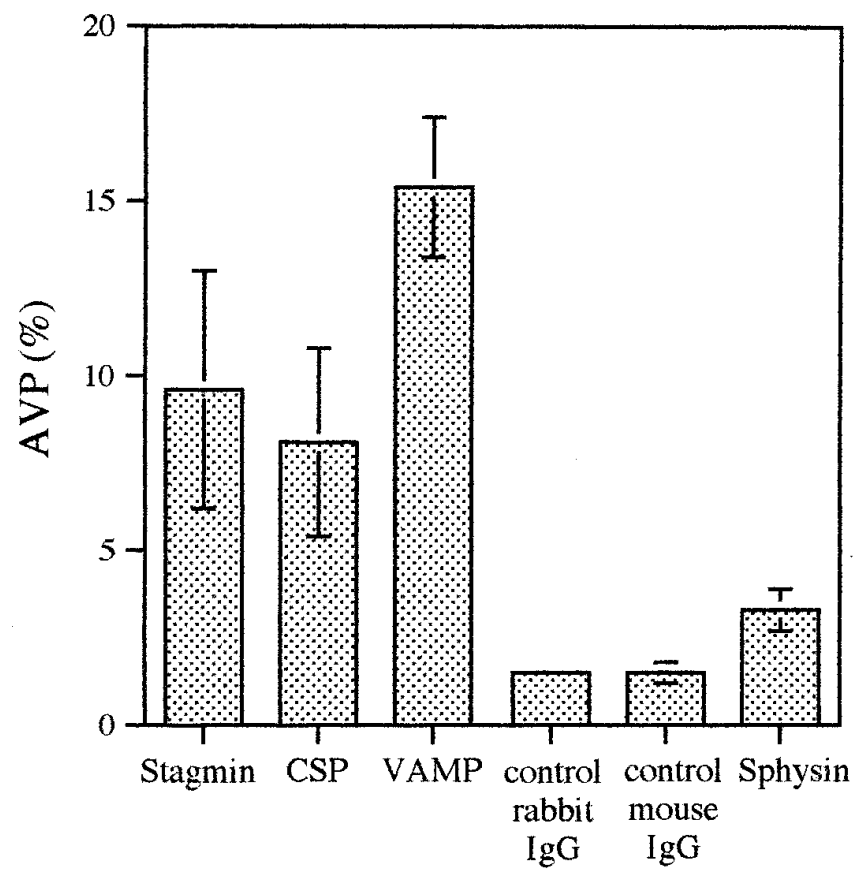

Figure 4. Immunoisolation of vesicles containing AVP. A postsynaptosomal supernatant $(0.1 \mathrm{ml})$ containing vesicles released during homogenization of the rat neurohypophysis was incubated in a final volume of 0.2 $\mathrm{ml}$ with $10 \mu \mathrm{g}$ antibodies against synaptotagmin, csp, VAMP, synaptophysin, and control rabbit or mouse IgG. Vesicles were recovered with Protein A-Sepharose Fast Flow beads. After washing the pellets, the amount of AVP released by $1 \%$ Triton X-100 was determined by radioimmunoassay. Results are presented as a percentage of the total immunoreactive AVP that was pelleted by centrifugation at $100,000 \times g$ for $2 \mathrm{hr}$, which was 1.2 $\mathrm{ng} / 0.1 \mathrm{ml}$ postsynaptosomal supernatant.

(Figs. 2, 4), they did not reveal csp-calcium channel complexes. Similar results were obtained after solubilization in Triton X-100, digitonin, or Mega-9 (data not shown). Furthermore, no interaction between solubilized N-type calcium channels and immobilized MBP-csp was detected (data not shown). These results do not support the hypothesis that a stable association between csp and $\mathrm{N}$-type calcium channels can occur in nerve terminals from whole brain or the neurohypophysis.

\section{DISCUSSION}

Csps are lipidated proteins distributed extensively throughout the CNS and certain non-neuronal tissues (Kohan et al., 1995; Chamberlain and Burgoyne, 1996; Chamberlain et al., 1996; Coppola and Gundersen, 1996). At least two kinetically distinct modes of regulated exocytosis occur in the CNS involving either SSVs or LDCVs. Docked SSVs release their contents within 1 millisecond of calcium rise (Sabatini and Regehr, 1996), whereas the latency for exocytosis of peptides from neuroendocrine cells is approximately 10-fold greater (Thomas et al., 1993). Csps have been localized to synaptic vesicles (Mastrogiacomo et al., 1994) and in Drosophila, they play an essential role in rapid transmitter release from the nerve terminal (Umbach et al., 1994; Zinsmaier et al., 1994). It is not currently known whether csps are associated with brain LDCVs that support slower neurosecretory processes. Therefore, we have examined the expression and subcellular distribution of csps in peptidergic nerve terminals, which contain both SSVs and LDCVs, from the rat neurohypophysis.

Two csp variants have been reported, the smaller of which (csp2) would result in a truncated protein with a $3.3 \mathrm{kDa}$
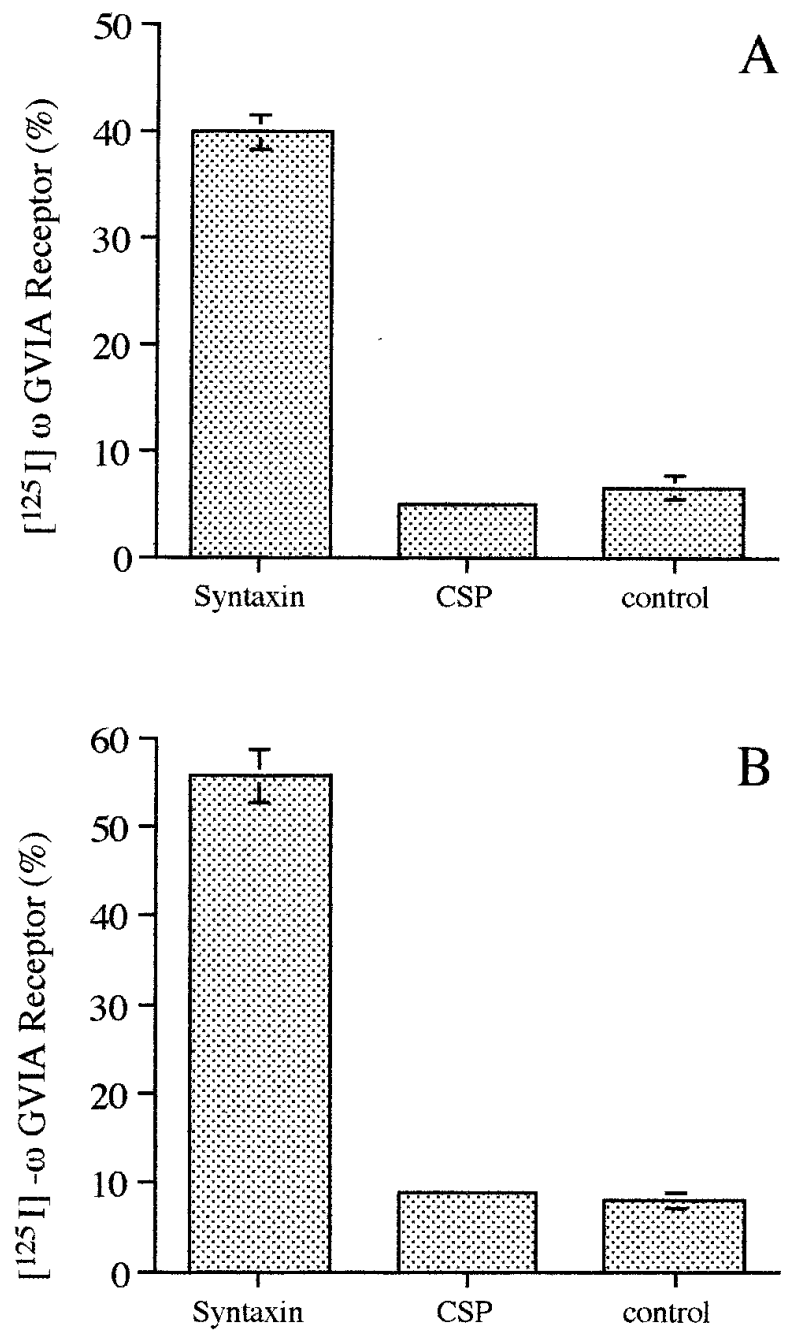

Figure 5. N-type calcium channels in brain and neurohypophysis were not co-immunoprecipitated with cysteine string proteins. N-type calcium channels in neurohypophysial nerve terminals $(A)$ or brain P2 membranes $(B)$ were prelabeled with $0.1 \mathrm{~nm}\left[{ }^{125} \mathrm{I}\right] \omega \mathrm{GVIA}$, extracted with $1 \%$ CHAPS, and incubated with antibodies $(20 \mu \mathrm{g} / 0.2 \mathrm{ml})$ against syntaxin 1 , csp, or control IgG. Immune complexes were recovered on Protein A-Sepharose Fast Flow beads. Radioactivity was counted and shown as a percentage of the total channel-bound radioligand in the assay.

reduction in molecular mass (Chamberlain and Burgoyne, 1996; Coppola and Gundersen, 1996). We have used a fusion protein containing the entire coding sequence of rat csp1 to raise polyclonal antibodies that should react with csp1 and 2 . Isolated nerve terminals from the neurohypophysis contained csp migrating at $36 \mathrm{kDa}$, which on delipidation yielded a single band with an apparent molecular mass of $27 \mathrm{kDa}$. By these criteria, csps in peptidergic terminals were indistinguishable from those in a total brain P2 fraction and apparently constitute a single protein species. These results are consistent with PCR amplification from rat brain mRNA, which detected only csp1 (Chamberlain and Burgoyne, 1996).

Subcellular fractionation of the neurohypophysis revealed at least two vesicle populations with distinct sedimentation properties corresponding to SSVs and LDCVs. This interpretation was supported by the fact that synaptophysin was detected only in the lighter vesicular peak, whereas AVP predominated in the heavier vesicular fractions and was not detected in fractions containing 
synaptophysin. Csp and VAMP displayed a similar distribution, suggesting that these two proteins are present in both microvesicles and LDCVs. The fact that anti-csp and antisynaptophysin antibodies were able to capture a similar fraction of total synaptophysin is consistent with csp being a constituent of SSVs. Furthermore, the presence of csp, VAMP, and synaptotagmin in LDCVs that contain AVP was confirmed by immunoisolating vesicles on immobilized antibodies and assaying captured AVP. The detection of significant amounts of AVP at the top of sucrose gradients is presumably attributable to LDCV lysis. Although we have not determined where broken LDCV membranes migrate in gradients, a previous report suggests co-sedimentation with SSVs (Walch-Solimena et al., 1993). Accordingly, we cannot rule out the possibility that a portion of csp immunoreactivity in the light fractions of sucrose gradients may be contributed by lysed LDCV membranes.

Early work suggested that VAMP is restricted to SSVs in the brain (Baumert et al., 1989). However, this is not consistent with the effects of clostridial neurotoxins on the secretion of neurohormones. The light chain of tetanus toxin blocks calcium-induced exocytosis of AVP in permeabilized nerve terminals, and the effect is prevented by synthetic peptides corresponding to cytoplasmic domains of VAMP1 or VAMP2 (Dayanithi et al., 1994). Our data now provide direct confirmation of the presence of VAMP in LDCVs in the CNS. These findings, together with recent reports demonstrating that VAMPs are associated with secretory granules in the pheochromocytoma line PC12 (Chilcote et al., 1995), are consistent with a general role for VAMP-like proteins in regulated secretion.

Csps, which were found to be present in both SSVs and LDCVs, may display a similar ubiquitous distribution pattern to VAMPs, because they are also expressed in non-neuronal tissues including adrenal chromaffin cells (Kohan et al., 1995; Chamberlain and Burgoyne, 1996), where they are associated with chromaffin granules (Chamberlain et al., 1996) and have been detected by immunoblotting in a zymogen granule fraction from the pancreas (Braun and Scheller, 1995).

In the brain, synaptophysin is thought to be a marker for SSVs, because immunogold labeling (Navone et al., 1986, 1989), density gradient fractionation, and immunoisolation of vesicular neuropeptide Y (Walch-Solimena et al., 1993) have failed to detect synaptophysin in LDCVs. However, secretory granules from adrenal chromaffin and PC12 cells, which are widely used as a model for neuronal LDCVs, do appear to contain synaptophysin. In chromaffin and PC12 cells, subcellular fractionation (Obendorf et al., 1988) and immunoisolation of $\left[{ }^{3} \mathrm{H}\right]$ norepinephrine-containing vesicles (Lowe et al., 1988) or secretogranin 1-containing vesicles (Chilcote et al., 1995) have provided strong evidence in favor of the presence of synaptophysin. Although we did not detect synaptophysin in LDCV fractions from the neurohypophysis by immunoblotting, anti-synaptophysin antibody beads recovered higher amounts of vesicular AVP than did control IgG. This inconsistency may be attributable to the higher sensitivity of the second procedure. Our data do not allow us to eliminate the possibility that synaptophysin is present, albeit at very low density, in brain LDCV membranes.

Syntaxin 1, a component of the synaptic core complex implicated in vesicle docking and fusion, has been shown to form a stable interaction with $\mathrm{N}$ - or $\mathrm{P} / \mathrm{Q}$-type calcium channels (Yoshida et al., 1992; Sheng et al., 1994; Martin-Moutot et al., 1996). A functional correlate of these findings was provided by the demonstration that the co-expression of syntaxin 1 with $\mathrm{N}$ - or Q-type calcium channels in Xenopus oocytes modified channel-gating properties (Bezprozvanny et al., 1995). The injection of cRNA encoding Torpedo csp enhances $\omega$ GVIAsensitive calcium currents in Xenopus oocytes expressing Torpedo electric lobe or rat brain mRNA (Gundersen and Umbach, 1992). It was suggested subsequently that the interaction between csp on a docked synaptic vesicle and the calcium channel may be required for channels to open in response to membrane depolarization (Mastrogiacomo et al., 1994). Therefore, we used a co-immunoprecipitation procedure to examine whether complexes containing csp and N-type calcium channels could be detected in detergent-solubilized nerve terminals. Approximately $50 \%$ of $\left[{ }^{125} \mathrm{I}\right] \omega \mathrm{GVIA}$ channels extracted from brain $\mathrm{P} 2$ or neurohypophysial nerve terminals was trapped by anti-syntaxin 1 antibodies but not by anti-csp antibodies. Coimmunoprecipitation has revealed the association of presynaptic calcium channels with a protein complex containing syntaxin, SNAP 25, VAMP, and synaptotagmin that is thought to play a role in locating docked vesicles within a microdomain of calcium entry (Yoshida et al., 1992; El Far et al., 1995; MartinMoutot et al., 1996). Our present findings do not support the view that csp is stably associated with this complex. However, we cannot eliminate the possibility that our anti-csp antibodies bind predominantly to epitopes that are masked in calcium channel-containing complexes or that labile molecular interactions may be disrupted during membrane solubilization. Furthermore, csp modulation of calcium channel activity may be indirect and not require the formation of csp-channel complexes. More work will be required to examine the mechanisms of channel regulation by csps.

\section{REFERENCES}

Augustine GJ, Burns ME, DeBello WM, Pettit DL, Schweizer FE (1996) Exocytosis: proteins and perturbation. Annu Rev Pharmacol Toxicol 36:659-701.

Baumert M, Maycox PR, Navone F, De Camilli P, Jahn R (1989) Synaptobrevin: an integral membrane protein of 18,000 daltons present in small synaptic vesicles of rat brain. EMBO J 8:379-384.

Bezprozvanny I, Scheller RH, Tsien RW (1995) Functional impact of syntaxin on gating of N-type and Q-type calcium channels. Nature 378:623-626.

Braun JEA, Scheller RH (1995) Cysteine string protein, a DnaJ family member, is present on diverse secretory vesicles. Neuropharmacology 34:1361-1370.

Burger PM, Mehl E, Cameron PL, Maycox PR, Baumert M, Lottspeich F, De Camilli P, Jahn R (1989) Synaptic vesicles immuno-isolated from rat cerebral cortex contain high levels of glutamate. Neuron 3:715-720.

Cazalis M, Dayanithi G, Nordmann J (1987) Hormone release from isolated nerve endings of the rat neurohypophysis. J Physiol (Lond) 390:55-70.

Chamberlain LH, Burgoyne RD (1996) Identification of a novel cysteine string protein variant and expression of cysteine string proteins in non-neuronal cells. J Biol Chem 271:7320-7323.

Chamberlain LH, Henry J, Burgoyne RD (1996) Cysteine string proteins are associated with chromaffin granules. J Biol Chem 271:19514-19517.

Chilcote TJ, Galli T, Mundigl O, Edelmann L, McPherson PS, Takei K, De Camilli P (1995) Cellubrevin and synaptobrevins: similar subcellular localization and biochemical properties in PC12 cells. J Cell Biol 129:219-231.

Coppola T, Gundersen C (1996) Widespread expression of human cysteine string proteins. FEBS Lett 391:269-272.

Cyr DM, Langer T, Douglas MG (1994) DnaJ-like proteins: molecular chaperones and specific regulators of Hsp70. Trends Biochem Sci 19:176-181.

Dayanithi G, Stecher B, Höhne-Zell B, Yamasaki S, Binz T, Weller U, Niemann H, Gratzl M (1994) Exploring the functional domain and the target of the Tetanus toxin light chain in neurohypophysial terminals. Neuroscience 58:423-431. 
El Far O, Charvin N, Leveque C, Martin-Moutot N, Takahashi M, Seagar M (1995) Interaction of a synaptobrevin (VAMP)-syntaxin complex with a presynaptic calcium channels. FEBS Lett 361:101-105.

Gundersen CB, Umbach JA (1992) Suppression cloning of the cDNA for a candidate subunit of a presynaptic calcium channel. Neuron 9:527-537.

Gundersen CB, Mastrogiacomo A, Faull K, Umbach JA (1994) Extensive lipidation of a Torpedo cysteine string protein. J Biol Chem 269:19197-19199.

Kohan SA, Pescatori M, Brecha NC, Mastrogiacomo A, Umbach JA, Gundersen CB (1995) Cysteine string protein immunoreactivity in the nervous system and adrenal gland of rat. J Neurosci 15:6230-6238.

Leveque C, El Far O, Martin-Moutot N, Sato K, Kato R, Takahashi M, Seagar M (1994) Purification of the N-type calcium channel associated with syntaxin and synaptotagmin. J Biol Chem 269:6306-6312.

Lowe AW, Madeddu L, Kelly RB (1988) Endocrine secretory granules and neuronal synaptic vesicles have three integral membrane proteins in common. J Cell Biol 106:51-59.

Martin TFJ (1994) The molecular machinery for fast and slow neurosecretion. Curr Opin Neurobiol 4:626-632.

Martin-Moutot N, Charvin N, Leveque C, Sato K, Nishiki T, Kozaki S, Takahashi M, Seagar M (1996) Interaction of SNARE complexes with $\mathrm{P} / \mathrm{Q}$-type calcium channels in rat cerebellar synaptosomes. J Biol Chem 271:6567-6570.

Mastrogiacomo A, Gundersen CB (1995) The nucleotide and deduced amino acid sequence of a rat cysteine string protein. Mol Brain Res 28:12-18.

Mastrogiacomo A, Parsons SM, Zampighi GA, Jenden DJ, Umbach JA, Gundersen CB (1994) Cysteine string proteins: a potential link between synaptic vesicles and presynaptic calcium channels. Science 263:981-982.

Navone F, Jahn R, Di Gioia G, Studenbrok H, Greengard P, De Camilli P (1986) Protein p38: an integral membrane protein specific for small vesicles of neurons and neuroendocrine cells. J Cell Biol 103:2511-2527.

Navone F, Di Gioia G, Jahn R, Browning M, Greengard P, De Camilli P (1989) Microvesicles of the neurohypophysis are biochemically related to small synaptic vesicles of presynaptic nerve terminals. J Cell Biol 109:3425-3433.

Obendorf D, Schwarzenbrunner U, Fischer-Colbrie R, Laslop A, Winkler $\mathrm{H}$ (1988) In adrenal medulla, synaptophysin (protein p38) is present in chromaffin granules and in a special vesicle population. J Neurochem 51:1573-1580.

Oho C, Seino S, Takahashi M (1995) Expression and complex formation of soluble $N$-ethyl-maleimide sensitive factor attachment protein (SNAP) receptors in clonal rat endocrine cells. Neurosci Lett 186:208-210.

Sabatini BL, Regehr WG (1996) Timing of neurotransmission at fast synapses in the mammalian brain. Nature 384:170-172.

Sheng ZH, Rettig J, Takahashi M, Catterall WA (1994) Identification of a syntaxin binding site on N-type calcium channels. Neuron 13:1303-1313.

Sheng ZH, Rettig J, Cook T, Catterall WA (1995) Calcium dependent interaction of $\mathrm{N}$ type calcium channels with the synaptic core complex. Nature 379:451-454.

Südhof TC (1995) The synaptic vesicle cycle: a cascade of protein-protein interactions. Nature 375:645-653.

Takahashi M, Arimatsu Y, Fujita S, Fujimoto Y, Kondo S, Hama T, Miyamoto E (1991) Protein kinase C and calmodulin-dependent protein kinase II phosphorylate a novel $58 \mathrm{kDa}$ protein in synaptic vesicles. Brain Res 551:279-292.

Thomas P, Wong J, Lee A, Almers W (1993) A low affinity $\mathrm{Ca}^{2+}$ receptor controls the final steps in peptide secretion from pituitary melanotrophs. Neuron 11:93-104.

Umbach JA, Zinsmaier KE, Eberle KK, Buchner E, Benzer S, Gundersen CB (1994) Presynaptic dysfunction in Drosophila csp mutants. Neuron 13:899-907.

Walch-Solimena C, Takei K, Marek KL, Midyett K, Süfhof TC, De Camilli P, Jahn R (1993) Synaptotagmin: a membrane constituent of neuropeptide-containing large dense-core vesicles. J Neurosci 13:3895-3903.

Yoshida A, Oho C, Omori A, Kuwahara R, Ito T, Takahashi M (1992) HPC-1 is associated with synaptotagmin and omega-conotoxin receptor. J Biol Chem 267:24925-24928.

Zinsmaier KE, Hofbauer A, Heimbeck G, Pflugfelder GO, Buchner S, Buchner E (1990) A cysteine-string protein is expressed in retina and brain of Drosophila. J Neurogenet 7:15-29.

Zinsmaier KE, Eberle KK, Buchner E, Walter N, Benzer S (1994) Paralysis and early death in cysteine string protein mutants of Drosophila. Science 263:977-982. 